\title{
Cement Leakage into Adjacent Vertebral Body Following Percutaneous Vertebroplasty
}

\author{
Jae Hoo Park', Hyeun Sung Kim², Seok Won Kim \\ ${ }^{I}$ Department of Neurosurgery, Chosun University College of Medicine, Gwangju, \\ ${ }^{2}$ Department of Neurosurgery, Nanoori Hospital, Suwon, Korea
}

Percutaneous vertebroplasty (PV) is a minimally invasive procedure for osteoporotic vertebral compression fractures that fail to respond to conventional conservative treatment. It significantly improves intolerable back pain within hours, and has a low complication rate. Although rare, PV is not free of complications, most of which are directly related to cement leakage. Because of its association with new adjacent fracture, the importance of cement leakage into the adjacent disc space is paramount. Here, we report an interesting case of cement leakage into the adjacent upper vertebral body as well as disc space following PV. To the best of our knowledge, there has been no report of cement leakage into the adjacent vertebral body following PV. This rare case is presented along with a review of the literature.

Key Words: Osteoporosis $\cdot$ Vertebroplasty $\cdot$ Leak

\section{INTRODUCTION}

Percutaneous vertebroplasty (PV) involves a minimally invasive percutaneous injection of polymethylmethacrylate (PMMA) within the vertebral body, and is a widely accepted procedure for osteoporotic vertebral compression fracture (VCF). Currently, it is becoming the standard treatment for osteoporotic VCF due to its efficacy of rapid pain relief and simplicity ${ }^{1,3)}$. However, cement leakage is a common problem, which can lead to other complications. Depending on the route, venous leaks, epidural leaks, and disc space leaks can occur' ${ }^{5}$. Among them, cement leakage into the adjacent disc space during PV occurs most commonly. It is well known that such leakage increases the risk of fracture of adjacent vertebral bodies due to increased mechanical pressure resulting from the cement ${ }^{6}$.

Here, we report a rare case of cement leakage into not only the disc space but also the adjacent upper vertebral body following PV, along with a review of the literature. To our knowledge, this is the first clinical report in the published literature to evaluate cement leakage into the adjacent vertebral body.

- Received: November 3, 2015 • Revised: January 17, 2016

- Accepted: January 18, 2016

Corresponding Author: Seok Won Kim

Department of Neurosurgery, Chosun University Hospital, Chosun

University School of Medicine, 365 Pilmun-daero, Dong-gu, Gwangju 61453, Korea

Tel: +82-62-220-3126, Fax: +82-62-227-4575

E-mail: ns64902@hanmail.net

$\otimes$ This is an open access article distributed under the terms of the Creative Commons Attribution Non-Commercial License (http://creativecommons.org/licenses/by-nc/4.0/) which permits unrestricted non-commercial use, distribution, and reproduction in any medium provided the original work is properly cited.

\section{CASE REPORT}

An 84-year-old woman was admitted to the Emergency Department. She had sustained severe back injury after falling from the bed 4 hours before admission. She had immediate enduring back pain, but there was no limitation in the straight leg raising test. Tenderness was noted in the overall back area, and she had marked limitation of postural change due to severe pain. The pain was relieved when she rested in bed. No sensory or motor deficits of the lower extremities were observed.

With suspicion of osteoporotic VCF, magnetic resonance imaging (MRI) and bone mineral densitometry were performed. MRI of the thoracolumbar spine revealed fresh VCFs at T9, L2, and L3. However, there was no cortical defect or displacement of the rear wall (Fig. 1). Dual-energy X-ray absorptiometry revealed severe osteoporosis of the spine (mean T-score, -5.8). Because of the intractable back pain and her old age, PV was performed on the day of admission. The procedure was performed under biplane fluoroscopy with use of local anesthesia on an outpatient basis.

Under biplane fluoroscopic guidance, we performed vertebroplasty at the level of $\mathrm{L} 2$ and $\mathrm{L} 3$, and there was no cement leakage. During injection of PMMA in the T9 vertebral body, however, cement leakage into the disc space and adjacent nonfractured upper vertebral body occurred (Fig. 2). Injection was halted as soon as leakage was noted. Approximately $4.5 \mathrm{~mL}$ of PMMA was injected. Although the cement had leaked into the disc space and upper vertebral body, the patient's mechanical back pain had remarkably improved. She was discharged with few complaints on the seventh postoperative day wearing a thoracolumbosacral orthosis. During the follow-up of more 


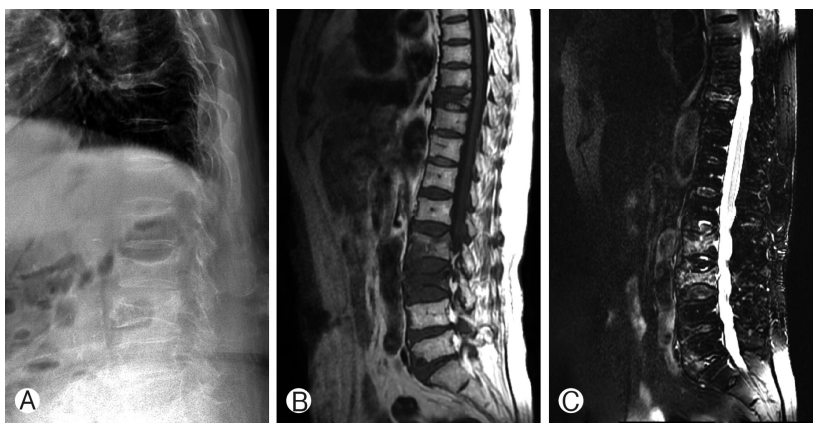

Fig. 1. Images of an 84-year-old woman with severe osteoporosis and compression fractures at T9, L2, and L3. Simple lateral radiograph (A) and T1-weighted (B) and fat-suppression (C) magnetic resonance images show fresh compression frac- tures at T9, L2, and L3.
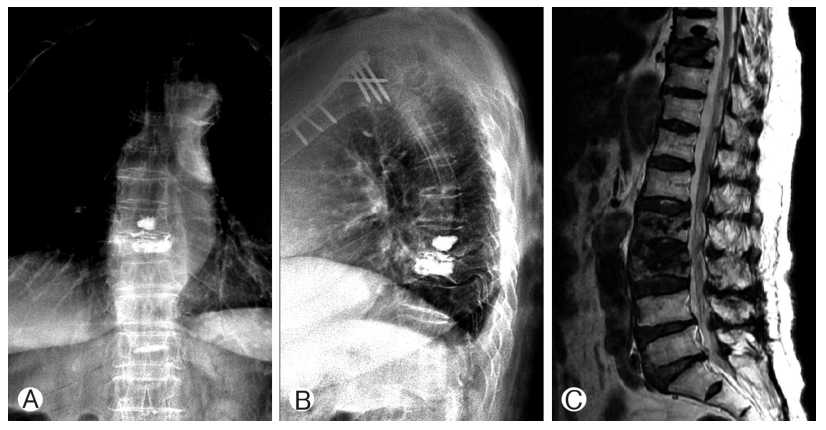

Fig. 2. Postoperative simple lateral radiographs (A, B) and T2weighted magnetic resonance image $(\mathrm{C})$ taken at 7 days after vertebroplasty reveal massive cement leakage into the adjacent upper vertebral body and disc space.

than 12 months, the patient was almost pain free with only mild back discomfort, and without new fracture of the adjacent vertebral body.

\section{DISCUSSION}

It is well known that PV is a minimally invasive procedure that provides rapid pain relief and stability for osteoporotic $\mathrm{VCF}^{7,9)}$. It is a widely accepted procedure for osteoporotic VCF due to its simplicity and efficacy. Significant pain relief can be achieved in over $90 \%$ of patients suffering from intractable osteoporotic VCF according to many studies ${ }^{1)}$.

However, several unexpected sequelae have been reported in the literature. Cement leakage or embolism outside the vertebral body during PV is one of the most common complications, even though it is usually clinically asymptomatic. New fracture of adjacent vertebral bodies often occurs after PV in clinical practice, especially in cases with cement leakage into the disc space. Whether these new adjacent fractures are associated with the natural progression of osteoporosis or are a consequence of augmentation with bone cement remain unclear.
Nonetheless, it is generally accepted that immediate increase in stiffness and strength in the treated vertebral body as well as improved mobility create new loads on the vertebral bodies ${ }^{10)}$. Cement leakage into the disc space also has been shown to increase the risk of new fracture of the adjacent vertebral body ${ }^{6,10)}$. These findings were confirmed by Komemushi et al. ${ }^{4}$, who found that cement leakage into the disc space was a significant predictor of new vertebral body fracture after PV.

We experienced significant cement leakage into the adjacent disc space and upper vertebral body. Several studies have reported the risk of cement leakage into the disc space ${ }^{2)}$. Nakano et al. ${ }^{8)}$ also insisted that old age, low bone mineral density, and short interval between injury and PV were associated with increased risk of cement leakage.

In our case, the patient had severe osteoporosis (mean Tscore, -5.8) and history of a recent fall. Regretfully, we did not perform computed tomography (CT) scan, but CT might give us more information for prevention from cement leakage into adjacent level. Due to her intractable pain and old age, we performed PV without attempting conservative treatment; thus, she had a short injury-to-PV interval. Patients with low bone mineral density have thinner trabeculae inside the vertebral body, which may result in more intertrabecular space through which mobile cement can pass. This difference may induce wide and unpredictable cement spread.

As a matter of fact, timing of PMMA cement injection is also important because low-viscosity cement carries a higher risk of extravasation. Therefore, in patients with severe osteoporosis, care should be taken during cement injection due to the high risk of cement leakage into the disc space and even the adjacent vertebral body.

\section{CONCLUSION}

We encountered a rare case of cement leakage into the adjacent disc space and upper vertebral body following PV. Our experience indicates that the factors mentioned above should be considered to reduce the risk of this unpredictable complication.

\section{CONFLICT OF INTEREST}

No potential conflict of interest relevant to this article was reported.

\section{REFERENCES}

1. Barr JD, Barr MS, Lemley TJ, McCann RM: Percutaneous vertebroplasty for pain relief and spinal stabilization. Spine (Phila Pa 1976) 25:923-928, 2000

2. Cotten A, Dewatre F, Cortet B, Assaker R, Leblond D, Duquesnoy B, et al: Percutaneous vertebroplasty for osteolytic metastases and myeloma: effects of the percentage of lesion filling and 
the leakage of methyl methacrylate at clinical follow-up. Radiology 200:525-530, 1996

3. Grados F, Depriester C, Cayrolle G, Hardy N, Deramond H, Fardellone P: Long-term observations of vertebral osteoporotic fractures treated by percutaneous vertebroplasty. Rheumatology (Oxford) 39:1410-1414, 2000

4. Komemushi A, Tanigawa N, Kariya S, Kojima H, Shomura Y, Komemushi S, et al: Percutaneous vertebroplasty for osteoporotic compression fracture: multivariate study of predictors of new vertebral body fracture. Cardiovasc Intervent Radiol 29: 580-585, 2006

5. Lee YG, Cha JH, Kim ES: Intradural Bone cement leakage following percutaneous vertebroplasty. Korean J Spine 5:33-35, 2008

6. Lin EP, Ekholm S, Hiwatashi A, Westesson PL: Vertebroplasty: cement leakage into the disc increases the risk of new fracture of adjacent vertebral body. AJNR Am J Neuroradiol 25:175-180, 2004

7. Murphy KJ, Deramond H: Percutaneous vertebroplasty in benign and malignant disease. Neuroimaging Clin N Am 10:535-545, 2000

8. Nakano M, Hirano N, Ishihara H, Kawaguchi Y, Matsuura K: Calcium phosphate cement leakage after percutaneous vertebroplasty for osteoporotic vertebral fractures: risk factor analysis for cement leakage. J Neurosurg Spine 2:27-33, 2005

9. Peh WC, Gilula LA, Peck DD: Percutaneous vertebroplasty for severe osteoporotic vertebral body compression fractures. Radiology 223:121-126, 2002

10. Trout AT, Kallmes DF, Kaufmann TJ: New fractures after vertebroplasty: adjacent fractures occur significantly sooner. AJNR Am J Neuroradiol 27:217-223, 2006 